Revue d'histoire de l'Amérique française

REYUE D.HISTOIRE DE L'AMÉRIQUE FRANÇAISE

\title{
Collection CLASSIQUES CANADIENS. Éditions Fides : Montréal et Paris. 1956. Lilianne et Guy FREGAULT, Frontenac ; Marcel TRUDEL, Champlain ; Michel DASSONVILLE, Crémazie ; Benoît LACROIX, Saint-Denys-Garneau.
}

\section{Michel Brunet}

Volume 10, numéro 3, décembre 1956

URI : https://id.erudit.org/iderudit/301784ar

DOI : https://doi.org/10.7202/301784ar

Aller au sommaire du numéro

Éditeur(s)

Institut d'histoire de l'Amérique française

ISSN

0035-2357 (imprimé)

1492-1383 (numérique)

Découvrir la revue

Citer ce compte rendu

Brunet, M. (1956). Compte rendu de [Collection CLASSIQUES CANADIENS. Éditions Fides : Montréal et Paris. 1956. Lilianne et Guy FREGAULT, Frontenac ; Marcel TRUDEL, Champlain; Michel DASSONVILLE, Crémazie ; Benoît LACROIX, Saint-Denys-Garneau.] Revue d'histoire de l'Amérique française, 10(3), 445-447. https://doi.org/10.7202/301784ar d'utilisation que vous pouvez consulter en ligne. 
Collection Classiques Canadiens. Editions Fides: Montréal et Paris. 1956. Lilianne et Guy FREGAULT, Frontenac; Marcel TRUDEL, Champlain; Michel DASSONVILLE, Crémazie; Benoît LACROIX, Saint-Denys-Garneau.

Les Editions Fides viennent de lancer une nouvelle collection que les éducateurs progressistes et les étudiants sérieux accueilleront avec reconnaissance. Il y a trente ans, on accusait nos collèges d'enseigner la chimie et la physique sans avoir recours aux expériences de laboratoire. En histoire et en littérature, la même méthode ou plutôt la même absence de méthode a prévalu jusqu'à nos jours. Les collégiens s'initient trop souvent à l'histoire et à la littérature canadiennes sans prendre contact avec les documents et les textes. Ils apprennent par cœur et récitent machinalement les faits et les jugements que leur fournissent leurs maîtres et leurs manuels. La collection CLASSIQUES CANADIENS changera, espérons-le, cette façon de procéder.

Les éditeurs ont confié à des spécialistes la préparation de chaque petit volume. $M$. et Mme Frégault nous présentent un Frontenac qui savait écrire agréablement et ne manquait pas d'éloquence pour se défendre auprès de ses supérieurs. Cette éloquence semble même avoir induit en erreur la plupart des historiens. Ceux-ci se sont montrés plutôt indulgents envers un gouverneur dont les ambitions personnelles ont nui au progrès de la Nouvelle-France. Les compilateurs de la correspondance de Frontenac résument ainsi la question: "Enfant terrible de son époque, il a longtemps été l'enfant gâté des historiens. » L'introduction de Lilianne et Guy Frégault rétablit les faits. Les amateurs d'histoire romantique et romanesque en seront déçus. 
Ceux qui étudient le passé pour en acquérir une connaissance aussi objective que possible s'en réjouiront. N'est-il pas normal d'apprendre que les fondateurs de l'empire français d'Amérique, nos ancêtres, étaient des hommes comme les autres hommes?

Les écrits de Champlain nous révèlent un homme de vision. M. Trudel en profite pour souligner que le fondateur de Québec n'était pas un apôtre de l'agriculturisme. Ce navigateur et ce colonisateur du XVII ${ }^{e}$ siècle, engagé dans la course aux empires, a voulu doter la France d'une colonie commerciale permanente dans la vallée du Saint-Laurent.

M. Dassonville a raison de soutenir que Crémazie maniait mieux la prose que la poésie. Ses pages de critique, sa correspondance et son journal font oublier le poète "patriote et patriotique » au ton guindé pour lui substituer un homme qui a souffert et qui a réfléchi. Malheureusement, l'introduction du compilateur répète docilement les principaux thèmes éloquents et grandiloquents de notre histoire telle qu'expliquée par nos orateurs «patriotes et patriotiques ». Crémazie lui-même connaissait bien leur recette: "Faites rimer un certain nombre de fois gloire avec victoire, aïeux avec glorieux, France avec espérance; entremêlez ces rimes de quelques mots sonores comme notre religion, notre patrie, notre langue, nos lois, le sang de nos pères; faites chauffer le tout à la flamme du patriotisme et servez chaud. Tout le monde dira que c'est magnifique. » Si Crémazie revenait, il constaterait que ses compatriotes - et son propre compilateur - continuent à entretenir religieusement les mêmes habitudes et les mêmes chimères. D'ailleurs, son poème « La mort du héros de Carillon » prévoit pour les vaincus de 1760 que: «L'illusion consolera leur vie. » Nos rêves «patriotes et patriotiques » sont tellement préférables à la dure réalité !

Saint-Denys-Garneau compte de nombreux admirateurs. Le volume préparé par Benoît Lacroix permettra à nos collégiens de se familiariser avec un poète, un écrivain et un artiste qui a cherché l'absolu et n'a rencontré que des hommes faibles satisfaits d'une société faite à leur image. Ceux qui ne se désintéressent pas de l'avenir de la collectivité canadienne-française liront avec profit les pages où Saint-Denys-Garneau s'interroge sur les relations du national et de l'humain (pp. 77-82). L'auteur, comme l'immense majorité des intellectuels canadiens-français contemporains, n'accepte plus le nationalisme qu'on lui a prêché à l'école et au collège. Mais il n'a pas complètement la naïveté de croire que ses compatriotes pourront mieux atteindre l'humain en niant leur existence comme groupe et en s'accrochant parasitairement à une autre collectivité plus dynamique que la 
leur. Il écrit: «Un peuple se fait en agissant, en créant, c'est-àdire en communiquant. » Comment les Canadiens français pourront-ils agir, créer et communiquer comme peuple si on détruit tous leurs cadres autonomes ? C'est la question essentielle. Que les poètes et les artistes l'ignorent, cela se comprend. Quand des sociologues, des économistes et des chefs politiques font preuve de la même ignorance, c'est le signe de notre désorientation collective après deux cents ans de pression assimilatrice.

En terminant, souhaitons que nos éducateurs et nos étudiants utilisent immédiatement ces premiers volumes de la collection. Leur réponse encouragera les Editions Fides à poursuivre cette initiative heureuse pour améliorer notre enseignement de l'histoire et de la littérature nationales. Ces parentes pauvres des programmes d'études finiront peut-être par prendre l'importance qu'elles doivent avoir dans toute formation dite humaniste.

Université de Montréal

Michel BRUNET

N.B. - La Revue d'histoire de l'Amérique française vivrait confortablement avec 100 nouveaux abonnés. 